\title{
EUROPEAN HERITAGE CONSUMERS AND THEIR INVOLVEMENT: A CULTURAL MARKETING PERSPECTIVE
}

\author{
Călin Vegheș ${ }^{1}$
}

DOI: https://doi.org/10.31410/ERAZ.2019.379

\begin{abstract}
Cultural heritage involvement and participation in the European Union are fairly modest: lack of interest, cost and lack of time are the main reasons, but the absence of a marketing vision also contributes to this overall limited cultural experience.

Paper defines the heritage involvement under a cultural marketing perspective, based on the inclination to discover, explore, experience and enjoy, and advances a corresponding classification of the heritage consumers, at the level of the European Union, using data from the dedicated Special Eurobarometer of the European Commission.
\end{abstract}

Keywords: Cultural experience, heritage involvement, cultural marketing, European Union.

\section{INTRODUCTION}

$\mathrm{T}$ here are several definitions of reference given to the cultural heritage but most of them have a strong technical character aiming to provide an exhaustive description of its content. From a marketing perspective, expressing essentially a consumer-oriented view over the subject, the definition given by the ICOMOS International Cultural Tourism Committee (2002) is the most appropriate due to its emphasis on the experiences the heritage explorers may enjoy: expressions of the ways of living developed by a community and passed on from generation to generation, including customs, practices, places, objects, artistic expression and values. Cultural heritage takes the forms of tangible (places of human habitation, villages, towns and cities, buildings, structures, art works, documents, handicrafts, musical instruments, furniture, clothing and items of personal decoration, religious, ritual and funerary objects, tools, machinery and equipment, and industrial systems) or intangible (all forms of traditional and popular or folk culture, the collective works originating in a given community and based on tradition - oral traditions, customs, languages, music, dance, rituals, festivals, traditional medicine and pharmacopeia, popular sports, food and the culinary arts and all kinds of special skill connected with the material aspects of culture) heritage [6].

In the words of Sandford (2019), heritage is something from the past, in the present, for the future consisting of what is passed to the next generation through mechanisms that enable taking present steps to pass on those aspects of the past that are valued, aspects that have a different object and play a different role in the private and public life, at different times [7]. Aiming to enrich the meaning of the term and to expand its coverage, Barrère (2016) has widened the word "heritage" using the plural - heritages - to include not just the "official" and "institutional" components (such as museums, libraries, archaeological and historic sites, archives), but also all those resulting from the accumulation and sedimentation of creativity, by the history that develops and passes culture through to society, with individuals, families, companies, industries, territories, societies, and, in the end, humanity as inheritors of these veritable resources from the past [2].

Bucharest University of Economic Studies, 41 Dacia Blvd., Sector 1, București, Romania 
Remarking that heritage does not actually exist until any specific elements inherited from the past, as well as those created in the present, are identified and labelled as such according to the current preferences, Babić (2015) advances the idea that, besides the economic exploitation, the "sincere" socially responsible heritage management must also take into account the socio-political features of heritage by answering the questions: why do we consider heritage and care for heritage important, who defines it and how, what affects and determines our position towards it, and, finally, who controls it and how, on whose behalf and to what purpose? [1]. Connecting the heritage and tourism, $\mathrm{Yu}$ and $\mathrm{Xu}$ (2019) have reviewed the studies in the field and observed that there are four interrelated dimensions in approaching the topic: the geographic scale covered; coverage of heritage resources; capacity of the heritage resources to create products for tourist consumption; and the structural strategy used to organize the rich heritage resources [10]. Discussing the increasingly pressing demand for heritage in hypermodern societies, Gravari-Barbas (2018) notes that not only heritage was a driver for tourism, but also tourism played an important role in the production of heritage, both in symbolic and physical terms, since from the $19^{\text {th }}$ century, becoming an essential factor of heritage globalization (patrimonialisation), contributing to the production of an increasing diversity of heritage artifacts, and becoming a "heritage production machine" [5].

Santa-Cruz and López-Guzmán (2017) have found in the literature approaching the subject of heritage tourism an orientation toward the heritage consumer, in this case the heritage tourist, advancing the idea that this is not just a simple visitor of heritage or cultural attractions but a person visiting a place with heritage attributes, aware of and motivated by those attributes seen as a part of his or her own heritage [8]. Under a context in which cultural heritage can be seen as a cornerstone of the local, regional, national and European identity, and one of the most important resources to be handled in the regional development, Bujdosó et al. (2015) affirm that this effort should aim the consumers and their experience, production being carried out with their active inclusion the main purpose being is to create memorable experiences [3].

Refocusing from the heritage itself and its management to its consumer, with its particular needs, demands and expectations, represents a real challenge both in theory and in practice, as well as one of key drivers of the cultural heritage capitalization. The undergoing conceptual and operational transition from cultural economics, via cultural management, to cultural marketing should consider, as Thurley (2005) suggested, the heritage cycle centered on consumer and including the successively inter-connected stages of heritage understanding, valuing, carrying and enjoying [9]. This heritage consumer-oriented approach inspires to investigate the relationships between the proper capitalization of the cultural heritage and the involvement of the heritage consumer supported by four heritage consumer behaviours: the interest to discover the heritage, the desire to explore it, the experience acquired after getting in touch with it and the further willingness to enhance the experience by enjoying it. In few words, the heritage involvement of the consumer is the result of the interest, desire and willingness to discover, explore, experience and enjoy cultural heritage sites and/or activities.

\section{METHODOLOGICAL NOTES}

The assessment of the heritage consumers' involvement from a cultural marketing perspective has been conducted considering a set of four research variables related to the main heritage related behaviors - discovery, exploration, experiencing and enjoyment, with the involvement seen as the result of the joint action of these conducts. 
Conceptual definition of the research variables has been done considering the relevant definitions included in the Special Eurobarometer 466 on Cultural Heritage [4] as it follows:

1. Heritage Discovery (HDS): the extent to which heritage consumers are aware about the monuments, works of art, sites, traditional events or festivals located and/or happening nearby their living areas of the consumers. The specific subvariables are: (1.1.) HDS1: historical monuments or sites (palaces, castles, churches, archaeological sites, gardens, etc.); (1.2.) HDS2: works of arts in museums and galleries (excepting the commercial galleries); (1.3.) HDS3: traditional events or festivals.

2. Heritage Exploration (HEX): the specific weight of the heritage consumers visiting monuments, works of art, sites and/or attending traditional events or festivals. The specific subvariables are: (2.1.) HEX1: visiting libraries or archives (to consult manuscripts, documents, ancient maps, etc.); (2.2.) HEX2: visiting historical monuments or sites (palaces, castles, churches, archaeological sites, gardens, etc.); (2.3.) HEX3: visiting museums and galleries; (2.4.) HEX4: attending traditional events (food festivals, carnivals, puppet theatres, floral festivals, etc.); (2.5.) HEX5: visiting traditional craft workplaces (weaving, glass blowing, decorative art, embroidery, making musical instruments or pottery, etc.); (2.6.) HEX6: going to the cinema or a film heritage festival to see a classic European film produced at least ten years ago); (2.7.) HEX7: attending a traditional or classical performing arts event (music, including opera, dance or theatre, folk music, etc.).

3. Heritage Experience (HXP): main factors of heritage consumer satisfaction defined in marketing terms (products, prices, placement, promotion, personnel, physical evidence and processes). The specific subvariables are: (3.1.) HXP1: choice of cultural heritage sites or activities; (3.2.) HXP2: cost of accessing cultural heritage sites or activities; (3.3.) HXP3: accessibility of the cultural heritage sites or activities; (3.4.) HXP4: information regarding the cultural heritage sites or activities; (3.5.) HXP5: quality of the cultural heritage sites or activities.

4. Heritage Enjoyment (HEY): ways in which heritage consumers participate actively and enjoy the cultural heritage. The specific subvariables are: (4.1.) HEY1: regularly visiting sites (such as monuments, museums, etc.) or going to events (such as festivals, concerts, etc.); (4.2.) HEY2: doing a traditional activity (such as traditional dancing or singing, playing traditional music, traditional cooking, etc.); (4.3.) HEY3: voluntarily working for an organisation (a museum, an association, a foundation, etc.) that is active in the field of cultural heritage; (4.4.) HEY4: donating money or other resources to an organisation (a museum, an association, a foundation, etc.) that is active in the field of cultural heritage (conserving monuments and paintings, keeping alive traditions, developing education programmes, etc.).

Measurement of the heritage involvement has been conducted converting the percentages provided in the Special Eurobarometer 466 for each of the above-mentioned variables and sub-variables (at the level of each of the European Union member states) in scores expressed on a scale from 1 (lowest) to 5 (highest), followed by calculating average scores for each sub-variable, aggregating the average sub-variable scores into average scores of the research variables and, finally, aggregating average variable scores in a single average score of the heritage involvement. 


\section{MAIN FINDINGS}

The involvement of the European heritage consumers can be assessed as relatively moderate $(\mathrm{HER}=2.83)$ : the positive experiences registered visiting or attending cultural heritage sites or activities $(\mathrm{HXP}=4.28)$ are the main (and, unfortunately, single) driver of this involvement, while discovering (HDS=2.79), exploring ( $\mathrm{HEX}=2.67)$ and particularly enjoying $(\mathrm{HEY}=1.57)$ cultural heritage sites and/or activities are lowering it significantly (see Figure 1). The European heritage consumers seem to have a relatively moderate interest to discover, a similarly limited desire to explore and an even poorer openness to enjoy the cultural heritage. Although getting in touch with cultural heritage sites or activities generates an overall satisfactory experience, the European consumers do not enjoy the heritage by regularly visiting sites or going to events, doing a traditional activity, voluntarily working for or donating money or other resources to an organisation that is active in the field.

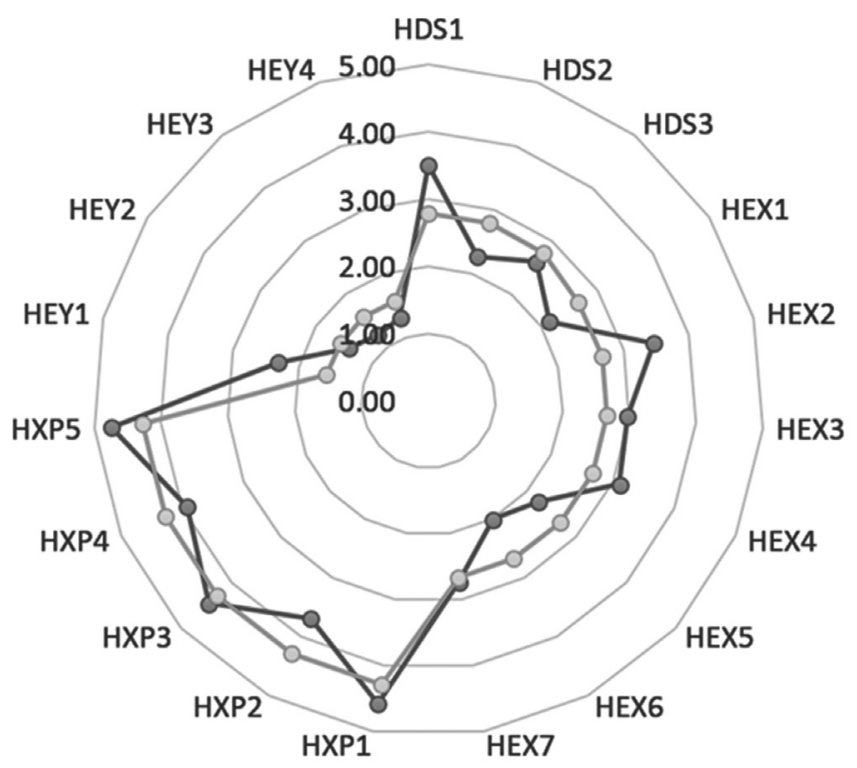

Figure 1. European heritage consumers involvement in terms of their appetence to discover, explore, experience and enjoy cultural heritage sites and/or activities

The European heritage consumers have a relatively moderate intention to discover cultural heritage sites or activities (HDS=2.79). Monuments and sites, such as palaces, castles, churches, archaeological sites, and gardens (HDS1=3.50), tend to be more interesting by comparison to the works of arts displayed in museums and galleries (HDS2=2.26) or the traditional events or festivals (HDS3 $=2.21$ ). It could be a matter of significance (as monuments and sites bear an important historical connotation due to their association with well-known or relevant personalities and events), physical evidence (as monuments and sites are more conveniently located and, thus, more easily accessible for the potential visitors) or accessibility (in terms of openness to wider audiences being positioned rather as mass culture objects or activities by comparison to the art works or classical performing arts events that may be perceived as addressing a high-culture audience).

Somehow surprisingly, the European heritage consumer appears to be even less interested to explore $(\mathrm{HEX}=2.67)$ the cultural heritage sites or activities they already discovered. Visiting historical monuments and sites (HEX2=3.46), attending traditional events (HEX4=3.11), visiting museums and galleries $(\mathrm{HEX} 3=2.97)$ and attending traditional or classical performing arts events $(\mathrm{HEX} 7=2.74)$ are the most frequent, while visiting traditional craft workplaces (HEX5=2.22), visiting libraries or archives $(\mathrm{HEX1}=2.16)$ and going to the cinema or film heritage festivals $(\mathrm{HEX} 6=2.01)$ are the least 
frequent ways of exploring the cultural heritage. Besides the overall modest level of exploring the cultural heritage range of sites or activities, the scores express with a reasonable accuracy the perceptions European heritage consumers associate to these ways of exploring cultural heritage: while historical monuments, sites, traditional events, museums, galleries or even some of the traditional or classical performing arts events are perceived as addressing a wider, mass audience, traditional craft workplaces, libraries and archives, cinema and film festivals are perceived as addressing a rather niched public (as having a strong interest in glass blowing, embroidery, pottery or even decorative art, consulting manuscripts, documents and ancient maps or even seeing classic European films produced at least a decade ago may be a feature of a very narrow market segment).

The experiences generated as a result of the discovery and exploration of the cultural heritage have been assessed considering the background provided by the choice, cost of accessing, easiness of accessing, related information and overall quality of the cultural heritage sites and activities interpreted correspondingly as marketing mix elements (product, price, placement, promotion and a synthesis of the personnel, physical evidence and processes). Although less interested to discover and explore cultural heritage, the European consumer has a more than favorable experience $(\mathrm{HXP}=4.28)$ visiting sites and attending activities of a very good overall quality (HXP5=4.75), having at disposal a generous $(\mathrm{HXP} 1=4.57)$ and quite accessible $(\mathrm{HXP} 3=4.46)$ choice of cultural heritage sites or activities. A certain lack of information (HXP4=3.93) and a relatively high cost $(\mathrm{HXP} 2=3.68)$ may affect the experience but, in overall terms, experiencing cultural heritage and sites proves to be very satisfactory. The low or relatively low percentages of the consumers indicating lack or limited choice (12\%), remoteness of difficult access $(12 \%)$, overall quality $(6 \%)$ or even lack or information ( $25 \%)$ and cost (34\%) as main barriers to experience cultural heritage sites and activities suggests, on a hand, that the real challenge is not to provide a high quality experience but to convince consumers to become interested in having it and, on the other hand, that a high quality experience involves a cost that must be accepted and paid by the heritage consumer.

Discovering, exploring and experiencing cultural heritage sites or activities should be followed by enjoying the heritage in all its forms. Unfortunately, this is not happening as the heritage enjoyment score reveals (HEY=1.57). The relatively low interest in discovering and exploring cultural heritage is not balanced by the positive experience and the European heritage consumers are not inspired enough to regularly visit sites or going to events $(\mathrm{HEY} 1=2.31)$, doing a traditional activity (HEY2=1.42), donating money (HEY4=1.30) or working as volunteers (HEY3=1.24) for an organisation that is active in the field. Is cultural heritage experience just a one-stop shop experience? For the most part of the European consumers, yes, as with the exception of visiting regularly sites (such as monuments, museums, etc.) or going regularly to cultural events (such as festivals, concerts, etc.), mentioned by $31 \%$ of the European heritage consumers, doing a traditional activity (traditional dancing or singing, playing traditional music, traditional cooking, etc.), donating money or other resources to or working voluntarily for an organisation (a museum, an association, a foundation, etc.) that is active in the field are exceptional behaviors localised at the level of very narrow segments.

\section{CONCLUSION}

The assessment of the heritage involvement of the European consumer leads to a paradoxical conclusion: although the experience obtained getting in touch with the cultural heritage sites and/or activities appears to be positive, the interest to discover and desire to explore are both modest, while the later enjoyment of this heritage is very low. This, on a hand, confirms that lack of interest and time (mentioned by 37 , respectively $34 \%$ of the heritage consumers) are 
the main causes of this rather reserved attitude of the European consumers toward the cultural heritage and, on the other hand, indicates the areas in which further efforts to promote and capitalize cultural heritage should be directed: creating and communicating cultural products, services and activities that are appealing for consumers and capable to attract their interest and stimulate their desire to discover, explore, experience and, later, enjoy them.

The results of this exploratory approach should be considered within the limits of the research regarding, first, the considered variables and sub-variables (adaptations in the context of the Special Eurobarometer variables, not covering completely the investigated area but still allowing investigating the involvement of the European heritage consumer), and, second, the measurement of the variables and sub-variables in terms of aggregating the sub-variables, respectively variables scores to generate average heritage discovery, exploration, experience and enjoyment, respectively involvement scores (considering a discussable equal importance of all the involved sub-variables and variables). Still, the results will serve as a base for the future research aiming to improve the definition of the model variables, to measure the impact of heritage discovery, exploration, experience, enjoyment over the involvement of heritage consumer, and to assess the impact of the heritage involvement over the capitalization of the cultural heritage in connection with the sustainable development of the local communities.

\section{REFERENCES}

[1] Babić, D. (2015) Social responsible heritage management-empowering citizens to act as heritage managers, Procedia - Social and Behavioral Sciences 188, 27-34.

[2] Barrère, C. (2016) Cultural heritages: From official to informal, City, Culture and Society 7, 87-94.

[3] Bujdosó, Z., Dávid, L., Tőzsér, A., Kovács, G., Major-Kathi, V., Uakhitova, G., Katona, P., Vasvári, M. (2015) Heritage as an Alternative Driver for Sustainable Development and Economic Recovery in South East Europe, Procedia - Social and Behavioral Sciences 188, 307-315.

[4] European Commission (2017) Special Eurobarometer 466 - October 2017 Cultural Heritage Report, http://ec.europa.eu/commfrontoffice/publicopinion/index.cfm/ResultDoc/ download/DocumentKy/80882.

[5] Gravari-Barbas, M. (2018) Tourism as a heritage producing machine, Tourism Management Perspectives 26, 5-8.

[6] ICOMOS International Cultural Tourism Charter (2002) Principles And Guidelines For Managing Tourism At Places Of Cultural And Heritage Significance, International Council on Monuments and Sites, ICOMOS International Cultural Tourism Committee, http:// www.icomos.no/wp-content/uploads/2014/04/ICTC-Charter.pdf.

[7] Sandford, R. (2019) Thinking with heritage: Past and present in lived futures, Futures 111, 71-80.

[8] Santa-Cruz, F.G., López-Guzmán, T. (2017) Culture, tourism and World Heritage Sites, Tourism Management Perspectives 24, 111-116.

[9] Thurley, S., Into the future. Our strategy for 2005-2010. Conservation Bulletin, Vol. 49, pp 26-27, 2005.

[10] Yu, X., Xu, H. (2019) Cultural heritage elements in tourism: A tier structure from a tripartite analytical framework, Journal of Destination Marketing \& Management 13, 39-50. 